\title{
Variants of GSK3 $\beta$ and SFRP4 genes in Wnt signaling were not associated with osteonecrosis of the femoral head
}

\author{
Yang Song ${ }^{1,3}$, Zhenwu Du, 1,2,3, Qiwei Yang ${ }^{2,3}$, Ming Ren ${ }^{1,3}$, Qingyu Wang ${ }^{2,3}$, Gaoyang \\ Chen $^{2,3}$, Haiyue Zhao ${ }^{2,3}$, Zhaoyan $\mathrm{Li}^{1,3}$ and Guizhen Zhang ${ }^{1,2,3}$ \\ ${ }^{1}$ Department of Orthopedics of Second Clinical College of Jilin University, Changchun, 130041, China \\ ${ }^{2}$ Research Centre of Second Clinical College of Jilin University, Changchun, 130041, China \\ ${ }^{3}$ The Engineering Research Centre of Molecular Diagnosis and Cell Treatment for Metabolic Bone Diseases of Jilin Province, \\ Changchun, 130041, China
}

Correspondence to: Guizhen Zhang, email: zhangguizhenjlu@163.com

Keywords: ONFH, SFRP4, GSK3 $\beta$, gene variants, Wnt signaling

Received: June 28, 2017 Accepted: August 08, $2017 \quad$ Published: August 22, 2017

Copyright: Song et al. This is an open-access article distributed under the terms of the Creative Commons Attribution License 3.0 (CC BY 3.0), which permits unrestricted use, distribution, and reproduction in any medium, provided the original author and source are credited.

\section{ABSTRACT}

Genome-wide association studies have identified that the gene variants in Wnt signaling associate with bone mineral density and fracture risk but the effects of the variants on the development of osteonecrosis of the femoral head (ONFH) have been unclear. Here, we analyzed the polymorphisms of 4 variants in GSK3 $\beta$ and SFRP4 genes of Wnt signaling and their association with the development of ONFH through Mass ARRAY ${ }^{\circledR}$ platform in 200 ONFH patients and 177 controls in Chinese population. Our results showed that the genotypes and allele frequencies of all variants detected in SFRP4 and GSK3 $\beta$ genes were not significantly different between patients and controls $(p>0.05)$; the correlation analysis between the 4 variants genotypes and gender, age at onset, etiological classification, unilateral or bilateral hip lesions, and clinical stages of ONFH, respectively, did not confirm significant association $(p>0.05)$ although age at onset in the minor homozygous(CC) carriers of SFRP4 rs1052981 (T/C) was a statistically younger tendency than that of the major homozygous (TT) or heterozygous (TC) of the SNP $(p=\mathbf{0 . 0 5 1})$; moreover, all haplotypes analyzed and their association with the clinical phenotypes of ONFH were also shown no statistical significance $(p>0.05)$. These results suggest that the 4 variants analyzed by this study in GSK3 $\beta$ and SFRP4 genes of Wnt signaling pathway are unlikely to be associated with susceptibility to ONFH.

\section{INTRODUCTION}

Wnt signaling pathway, as a crucial regulator of tissue homeostasis and remodeling, plays key roles in the transdifferentiation between osteogenesis and adipogenesis of bone marrow mesenchymal stem cells (BMMSCs) [1,2]. The Wnt family is comprised of 19 secreted cysteinerich glycoproteins. Depending on binding to one of the ten different Frizzled receptors and other coreceptors on the cell surface, they activate canonical, noncanonical, or both pathways for transcription of target genes [3]. The canonical Wnt signaling has been implicated in stimulating osteoprogenitor proliferation and osteogenesis [4]. The Wnt signaling represses adipogenesis by blocking the induction of CCAAT/enhance-binding protein- $\alpha$ (CEBPA) and peroxisome proliferator-activated receptor- $\gamma$ $(\mathrm{PPAR} \gamma)$, two master adipogenic transcription factors, and the disruption of $\mathrm{Wnt} / \beta$-catenin signaling leads to spontaneous adipogenesis [5].

Osteonecrosis of the femoral head (ONFH) is a complex disease caused by the interaction with the genetic and environmental factors [6]. Multiple gene variants have been proposed as the genetic risk factors of ONFH [7] but its molecular pathogenesis has been remained obscure. ONFH prevalence has been increased in recent decades [8]. Genome-wide association studies (GWAS) have identified that common variants of genes in Wnt signaling associated closely with bone mineral density 
(BMD) and risk of fracture, and several recent GWAS studies demonstrate that genetic variations in Wnt16 are correlated with BMD and risk of fracture in children and adults across multiple populations [9-11]. However, it has never been reported that the gene variants in the Wnt signaling associate with the development of ONFH. Here, we analyzed the genotypes, allele, haplotype frequencies of 4 variants of glycogen synthase kinase 3 beta (GSK3 $\beta$ ) and secreted frizzled-related protein 4 (SFRP4) genes in Wnt signaling and their association with the risk and clinical phenotypes of ONFH in $200 \mathrm{ONFH}$ patients and 177controls in Chinese population.

\section{RESULTS}

\section{Genotypes and allele frequencies of 4 variants in the SFRP4 and GSK3 $\beta$ genes between ONFH and control groups}

Genotypes and allele frequencies of 4 variants in the SFRP 4 and GSK3 $\beta$ genes are shown in Table $1 . \mathrm{X}^{2}$ test results showed that the genotypes of SFRP4 rs1052981 $(\mathrm{C} / \mathrm{T})$ and $\mathrm{rs} 1802073(\mathrm{~A} / \mathrm{C})$ between $\mathrm{ONFH}$ and control groups were no statistical significance, $p=0.161, p=0.494$, respectively; logistic regression analyses further revealed that all models in the two variants, including codominant, dominant, and recessive, failed to show statistical significance $(p>0.05)$; their allele frequencies were also no statistical difference between ONFH and control groups, $p$ $=0.202, p=0.351$, respectively. The genotypes of GSK3 $\beta$ rs3732361 (A/G) and rs3755557 (A/T) between ONFH and groups showed no statistical significance, $p=0.275$, $p=0.622$, respectively, and their allele frequencies were also not statistically different between $\mathrm{ONFH}$ and control groups, $p=0.938, p=0.830$, respectively.

\section{The association of 4 variants genotypes in the SFRP4 and GSK3B genes with the clinical phenotypes of ONFH}

We completed the correlation analysis between the 4 variants genotypes of SFRP4, GSK3 $\beta$ genes and gender, age at onset, etiological classification, unilateral or bilateral hip lesions, and clinical stages of ONFH, respectively. The results confirmed that all genotypes were not shown the statistical association with the clinical phenotypes of ONFH although age onset in the minor homozygous (CC) genotype carriers of SFRP4 rs1052981 $(\mathrm{T} / \mathrm{C})$ revealed statistically younger tendency than that of the major homozygous (TT) or heterozygous (TC) of the $\operatorname{SNP}(P=0.051)$ and the male proportion of heterozygous (TC) of $G S K 3 \beta$ rs 3755557 revealed a increased statistical tendency compared with the female proportion of the TC genotype, $P=0.067$, presented in Table 2 .

\section{The haplotypes of 4 variants in the SFRP4 and $G S K 3 \beta$ genes and their association with the clinical phenotypes of ONFH}

We calculated the Linkage disequilibrium (LD) coefficients between the 2 variants in the SFRP4 and GSK3 $\beta$ genes, respectively, using Shesis software platform (http://analysis.bio-x.cn/SHEsisMain.html) on the basic of the variants genotypes, shown in Figure 1. LD analysis reveals a stronger LD between rs3732361 and rs3755557 of GSK3 $\beta$ gene. Usually, single tag SNP in the stronger LD enough captures the genetic information of correlated variants. However, considering the two variants located in different function (3'UTR or promoter) region might affect their potential association with $\mathrm{ONFH}$, we still genotyped the two variants of $G S K 3 \beta$ gene and the
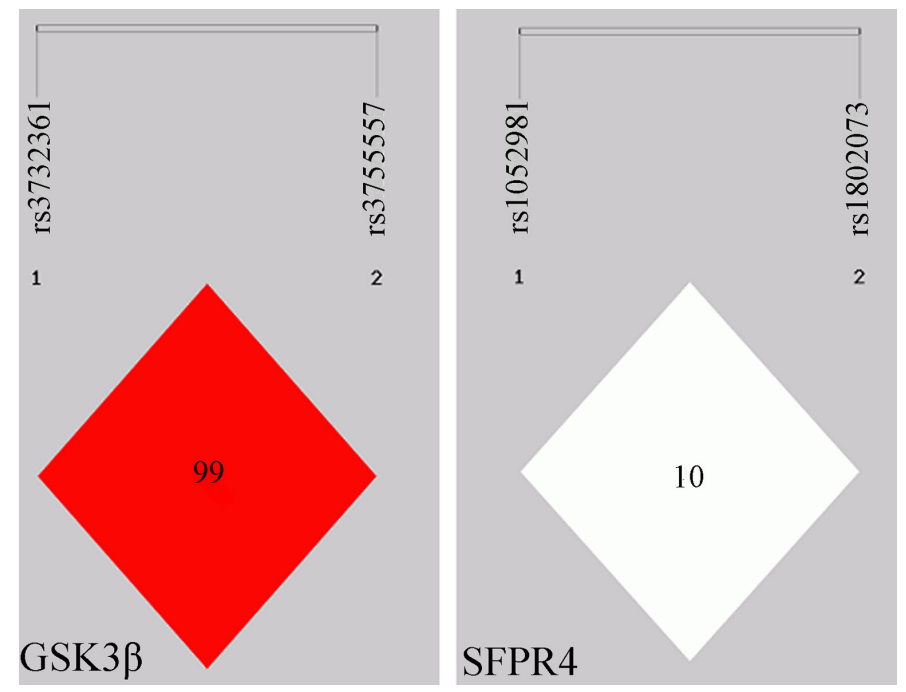

Figure 1: Linkage Disequilibrium (LD) map for the 4 variants in the GSK3ß and SFRP4 genes. Each diamond represents the correlation (D') between each pair of variants with darker shades representing stronger linkage disequilibrium. 
Table 1: Genotype and allele frequencies of the variants in the GSK3B and SFRP4 between ONFH patients and controls

\begin{tabular}{|c|c|c|c|c|c|c|c|c|c|c|c|c|}
\hline \multirow[t]{2}{*}{ Gene } & \multirow{2}{*}{ SNP ID } & \multirow{2}{*}{ Group } & \multicolumn{3}{|c|}{ Genotype (n) } & \multirow{2}{*}{ MAF } & \multirow{2}{*}{ HWE $^{\mathrm{a}}$} & \multirow{2}{*}{$p^{\mathrm{b}}$} & \multirow{2}{*}{$\begin{array}{c}\begin{array}{c}\text { Co-dominants } \\
(11 \text { vs. } 12 \text { vs. } 22)\end{array} \\
\text { OR }(95 \% \text { CI }) \\
P^{c}\end{array}$} & \multirow{2}{*}{$\begin{array}{c}\text { Dominants } \\
12+22 \text { vs. } 11 \\
\text { OR }(95 \% \mathrm{CI}) \\
P^{\mathrm{c}}\end{array}$} & \multirow{2}{*}{$\begin{array}{c}\text { Recessives } \\
22 \text { vs. } 11+12 \\
\text { OR }(95 \% \mathrm{CI}) \\
P^{\mathrm{c}}\end{array}$} & \multirow{2}{*}{$\begin{array}{c}\text { Allele } 2 \text { vs. } 1 \\
\text { OR }(95 \% \text { CI }) \\
P^{c}\end{array}$} \\
\hline & & & 11 & 12 & 22 & & & & & & & \\
\hline \multirow[t]{6}{*}{ GSK3 $\beta$} & rs3732361 (A/G) & & AA & $\mathrm{AG}$ & GG & & & & & & & \\
\hline & & Control & 51 & 94 & 31 & 0.443 & 0.276 & 0.275 & $1.036(0.760-1.412)$ & $0.882(0.549-1.416)$ & $1.315(0.763-2.267)$ & $\begin{array}{c}0.988(0.7311- \\
1.335)\end{array}$ \\
\hline & & Case & 55 & 75 & 37 & 0.446 & 0.238 & & 0.824 & 0.602 & 0.324 & 0.938 \\
\hline & rs $3755557(\mathrm{~T} / \mathrm{A})$ & & TT & $\mathrm{AT}$ & $\mathrm{AA}$ & & & & & & & \\
\hline & & Control & 130 & 42 & 4 & 0.142 & 0.781 & 0.622 & $0.971(0.632-1.491)$ & $1.028(0.640-1.649)$ & $0.462(0.083-2.578)$ & $0.955(0.630-1.449)$ \\
\hline & & Case & 143 & 49 & 2 & 0.137 & 0.324 & & 0.892 & 0.910 & 0.379 & 0.830 \\
\hline \multirow[t]{6}{*}{ SFRP4 } & rs1052981 (T/C) & & $\mathrm{TT}$ & CT & $\mathrm{CC}$ & & & & & & & \\
\hline & & Control & 96 & 68 & 13 & 0.266 & 0.841 & 0.161 & $0.824(0.572-1.188)$ & $0.878(0.569-1.355)$ & $0.457(0.157-1.329)$ & $0.799(0.566-1.128)$ \\
\hline & & Case & 101 & 68 & 5 & 0.224 & 0.103 & & 0.299 & 0.577 & 0.151 & 0.202 \\
\hline & rs $1802073(\mathrm{~A} / \mathrm{C})$ & & AA & $\mathrm{AC}$ & $\mathrm{CC}$ & & & & & & & \\
\hline & & Control & 47 & 87 & 43 & 0.489 & 0.827 & 0.494 & $1.106(0.820-1.493)$ & $1.330(0.814-2.174)$ & $0.985(0.607-1.597)$ & $0.872(0.654-1.163)$ \\
\hline & & Case & 42 & 104 & 51 & 0.477 & 0.415 & & 0.510 & 0.254 & 0.950 & 0.351 \\
\hline
\end{tabular}

11: homozygotes for the major allele, 12: heterozygotes and 22: homozygotes for the minor allele.

${ }^{a} p$-values of deviation from Hardy-Weinberg equilibrium between the ONFH group and control group.

$\mathrm{b} \chi^{2}$ test were used for frequencies of genotype analyses

c Logistic regression analyses were used for calculations. bold: $p$-value $<0.05$

results demonstrated that the two variants in stronger LD did show no any association with the development of ONFH. The haplotypes analysis shows that there are the 4 haplotypes of C-A, C-C, T-A, and T-C between rs $1052981(\mathrm{C} / \mathrm{T})$ and rs 1802073 of SFRP 4 gene and the 4 haplotypes were not shown significant difference between ONFH and control groups $(p>0.05)$ in spite of the decreased C-A haplotype frequency tendency of $\mathrm{ONFH}$ group, compared with control group, $P=0.073$. There are the 4 haplotypes of A-A, A-T, G-A, and G-T between rs3732361 (A/G) and rs3755557 (A/T) of GSK3 $\beta$ gene, and the haplotypes were not statistically different between ONFH and control groups $(P>0.05)$, shown in Table 3 . The haplotypes of SFRP 4 and GSK3 $\beta$ genes did not show significant association with the hip lesions of $\mathrm{ONFH}$ $(P>0.05)$, shown in Table 4 .

\section{DISCUSSION}

Wnt signaling functions, as a molecular switch, determine the balance between osteogenesis and adipogenesis of BMMSCs [12, 4]. BMMSCs are multipotent cells that can differentiate into adipocytes or osteocytes, and the functional changes of BMMSCs differentiation pathway may contribute to the pathogenesis of ONFH $[13,14]$. Moreover, interactions associated with the differentiation pathway of BMMSCs that promote adipogenesis and repress osteogenesis are considered as the major factors leading to steroid-related ONFH [15]. BMMSCs may differentiate preferentially into adipocytes rather than osteoblasts during the development of $\mathrm{ONFH}$ [16]. In view of the key roles of Wnt signaling in the differentiation of BMMSCs, we analysed the association of 4 variants in the SFRP4 and GSK3 $\beta$ genes of this pathway with the risk and clinical phenotypes of ONFH. Our results found that the genotypes, alleles, haplotypes frequencies of all detected variants in the SFRP4 and GSK3 $\beta$ genes were not significantly different between ONFH and controls groups; in order to explore the effects of the variants on the development of ONFH, we further completed the correlation analysis between the 4 variants genotypes and gender, age at onset, etiological classification, unilateral or bilateral hip lesions, and clinical stages of ONFH, respectively. These results further confirmed that all variants analyzed did not show statistical association with clinical phenotypes of ONFH, which suggests that the variants detected in this study are unlikely to be associated with susceptibility to ONFH.

SFRP4 is a member of the SFRP family that contains a cysteine-rich domain homologous to the putative Wntbinding site of frizzled proteins. SFRPs act as soluble modulators of Wnt signaling, and SFRP4 has been identified as a molecular link between islet inflammation and defective insulin secretion. SFRP4 influences a wide scope of genes of Wnt signaling and several genes variants from the pathway have been linked to the pathogenesis of Type 2 diabetes mellitus [17]. SFRP4 is secreted by multiple tissues including adipose tissue, which contributes the elevated circulating SFRP4 level in obesity [18]. The genetic studies provided evidence that recessive mutations in SFRP4 are a cause of Pyle's disease, and the mouse model in SFRP4 mutations reproduced the human phenotype to a remarkable degree, which showed that the phenotype was due to the differential regulation of Wnt signaling and BMP signaling. Deletion of SFRP4 activated predominantly canonical Wnt signaling in trabecular 
Table 2: The association of genotypes in the 4 variants of SFRP4 and GSK3 $\beta$ genes with clinical phenotypes of ONFH

\begin{tabular}{|c|c|c|c|c|c|c|c|c|c|c|c|c|c|}
\hline \multirow{2}{*}{ Gene } & \multirow[t]{2}{*}{ SNP IP } & \multirow{2}{*}{ Genotype } & \multicolumn{2}{|c|}{ Gender $n(\%)$} & \multirow{2}{*}{$\begin{array}{c}\text { Age on set } \\
\text { (yr) ANOWY }\end{array}$} & \multicolumn{3}{|c|}{$\begin{array}{c}\text { Etiological classification } \\
n(\%) \Delta\end{array}$} & \multicolumn{2}{|c|}{ Hip lesions $n(\%) \Delta$} & \multicolumn{3}{|c|}{ Clinical stages $n(\%) \Delta$} \\
\hline & & & Male & Female & & Alc $^{\mathrm{a}}$ & Ster & Idio & Unilateral & Bilateral & StageII & StageIII & StageIII \\
\hline \multirow{7}{*}{ SFRP4 } & \multirow{4}{*}{$\begin{array}{l}\text { rs } 1802073 \\
\text { (C/A) }\end{array}$} & $\mathrm{CC}$ & $29(24.6)$ & $15(25.9)$ & $46.9 \pm 13.5$ & $16(22.9)$ & $12(26.7)$ & $16(26.2)$ & $19(25.0)$ & $25(25.0)$ & $3(30.0)$ & $16(30.2)$ & $25(22.3)$ \\
\hline & & $\mathrm{CA}$ & $67(56.8)$ & $28(48.2)$ & $48.8 \pm 12.1$ & $37(52.9)$ & $23(51.1)$ & $35(57.4)$ & $44(57.9)$ & $51(51.0)$ & $5(50.0)$ & $26(49.1)$ & $64(56.6)$ \\
\hline & & AA & $22(18.6)$ & $15(25.9)$ & $46.9 \pm 13.5$ & $17(24.3)$ & $10(22.2)$ & $10(16.4)$ & $13(17.1)$ & $24(24.0)$ & $2(20.0)$ & $11(20.7)$ & $24(21.2)$ \\
\hline & & $P$ & \multicolumn{2}{|c|}{0.470} & 0.185 & \multicolumn{3}{|c|}{0.838} & \multicolumn{2}{|c|}{0.507} & \multicolumn{3}{|c|}{0.832} \\
\hline & \multirow{4}{*}{$\begin{array}{l}\text { rs1052981 } \\
(\mathrm{T} / \mathrm{C})\end{array}$} & TT & $63(59.4)$ & $27(54.0)$ & $46.0 \pm 11.9$ & $33(55.0)$ & $24(57.1)$ & $33(61.1)$ & $36(57.1)$ & $54(58.1)$ & $4(4.0)$ & $28(62.2)$ & $58(57.4)$ \\
\hline & & $\mathrm{TC}$ & $40(37.7)$ & $22(44.0)$ & $49.6 \pm 11.9$ & $25(41.7)$ & $16(38.1)$ & $21(38.9)$ & $27(42.9)$ & $35(37.6)$ & $6(60.0)$ & $16(35.6)$ & $40(39.6)$ \\
\hline & & $\mathrm{CC}$ & $3(2.8)$ & $1(2.0)$ & $36.7 \pm 9.8$ & $2(3.3)$ & $2(4.8)$ & $0(0.0)$ & $0(0)$ & $4(4.3)$ & $0(0)$ & $1(2.2)$ & $3(3.0)$ \\
\hline & & $P$ & \multicolumn{2}{|c|}{0.741} & 0.051 & \multicolumn{3}{|c|}{0.628} & \multicolumn{2}{|c|}{0.326} & \multicolumn{3}{|c|}{0.685} \\
\hline \multirow{8}{*}{ GSK3 $\beta$} & \multirow{4}{*}{$\begin{array}{l}\text { rs } 3732361 \\
(\mathrm{~A} / \mathrm{G})\end{array}$} & $\mathrm{AA}$ & $35(33.7)$ & $12(25.5)$ & $46.0 \pm 12.1$ & $20(34.5)$ & $16(39.0)$ & $11(21.2)$ & $22(36.7)$ & $25(27.5)$ & $2(20.0)$ & $15(34.1)$ & $30(30.9)$ \\
\hline & & $\mathrm{AG}$ & 45 (43.3) & $25(53.2)$ & $48.1 \pm 13.2$ & $22(37.9)$ & 17 (41.5) & $31(59.6)$ & $27(45.0)$ & $43(47.3)$ & $3(30.0)$ & $18(40.9)$ & $49(50.5)$ \\
\hline & & GG & $24(23.1)$ & $10(21.3)$ & $48.5 \pm 11.8$ & $16(27.6)$ & $8(19.5)$ & $10(19.2)$ & $11(18.3)$ & $23(25.3)$ & $5(50.0)$ & $11(25.0)$ & $18(18.6)$ \\
\hline & & $P$ & \multicolumn{2}{|c|}{0.492} & 0.587 & \multicolumn{3}{|c|}{0.145} & \multicolumn{2}{|c|}{0.408} & \multicolumn{3}{|c|}{0.207} \\
\hline & \multirow{4}{*}{$\begin{array}{l}\operatorname{rs} 3755557 \\
(\mathrm{~T} / \mathrm{A})\end{array}$} & $\mathrm{TT}$ & 83 (69.7) & $41(74.5)$ & $48.4 \pm 11.7$ & $49(71.0)$ & $35(74.5)$ & $40(69.0)$ & $0(0)$ & $2(2.0)$ & $8(80.0)$ & $38(71.7)$ & $78(70.3)$ \\
\hline & & $\mathrm{TA}$ & $36(30.3)$ & $12(21.8)$ & $45.3 \pm 13.5$ & $20(29.0)$ & $11(23.4)$ & $17(29.3)$ & 47 (65.3) & $77(75.5)$ & $2(20.0)$ & $14(26.4)$ & $32(28.8)$ \\
\hline & & $\mathrm{AA}$ & $0(0)$ & $2(3.6)$ & $46.0 \pm 10.0$ & $0(0)$ & $1(2.1)$ & $1(1.7)$ & $25(34.7)$ & $23(25.5)$ & $0(0)$ & $1(1.9)$ & $1(0.99)$ \\
\hline & & & \multicolumn{2}{|c|}{0.067} & 0.326 & \multicolumn{3}{|c|}{0.759} & \multicolumn{2}{|c|}{0.111} & \multicolumn{3}{|c|}{0.932} \\
\hline
\end{tabular}

a:Alc : Alcohol-induced, Ster: steroid- induced; Idio: idiopathic; ${ }^{\mathbf{}} \mathrm{X}^{2}$ text

Table 3: Haplotype analysis of GSK3 $\beta$ and SFRP4 genes in WNT signaling pathway

\begin{tabular}{lcccccc}
\hline \multicolumn{1}{c}{ SNPs } & Haplo-type & ONFH n (\%) & Control n (\%) & $\chi \mathbf{2}$ & $\boldsymbol{P}$ & OR (95\%CI) \\
\hline SFRP4 & C-A & $37.91(11.0)$ & $55.35(15.6)$ & 3.210 & $\mathbf{0 . 0 7 3 2}$ & $0.668(0.429 \sim 1.041)$ \\
rs1052981(C/T)- & C-C & $39.09(11.4)$ & $38.65(10.9)$ & 0.035 & 0.8517 & $1.046(0.653 \sim 1.676)$ \\
rs1802073(A/C) & T-A & $128.09(37.2)$ & $125.65(35.5)$ & 0.229 & 0.6326 & $1.078(0.792 \sim 1.468)$ \\
& T-C & $138.91(40.4)$ & $134.35(38.0)$ & 0.432 & 0.5109 & $1.107(0.817 \sim 1.501)$ \\
GSK33 & A-A & $45.99(13.8)$ & $49.99(14.2)$ & 0.026 & 0.871 & $0.965(0.627 \sim 1.486)$ \\
rs3732361 (A/G)- & A-T & $139.01(41.6)$ & $146.01(41.5)$ & 0.001 & 0.971 & $1.006(0.742 \sim 1.363)$ \\
rs3755557 (A/T) & G-T & $148.99(44.6)$ & $155.99(44.3)$ & 0.006 & 0.938 & $1.012(0.749 \sim 1.368)$ \\
& G-A & $0.01(0.0)$ & $0.01(0.0)$ & - & - & - \\
\hline
\end{tabular}

bone, leading to increased trabecular bone mass [19]. A study to detect the differentially expressed genes (DEGs) between ossified herniated discs and herniated discs without ossification showed that three of the top 20 DEGs, including sclerostin, WNT inhibitory factor 1 , and SFRP4 etc were correlated with the inhibition of Wnt pathway, which suggested that Wnt pathway abnormality and local inflammation may be correlated with disc ossification [20].

The protein encoded by GSK3 $\beta$ gene is a serinethreonine kinase, belonging to the glycogen synthase kinase subfamily. It involved in energy metabolism, neuronal cell development, and body pattern formation. Variants of $G S K 3 \beta$ gene have been implicated in relating to risk of Parkinson disease (PD), and studies in mice show that overexpression of this gene may be relevant to the pathogenesis of Alzheimer's disease. GSK3, as an enzyme of intracellular signaling and metabolic control of the cell, is among the molecular constraints which keep chondrocytes in the "arrested state" [21], and it belongs to the $\beta$-catenin degradation complex and acts by keeping an inactive phosphorylated form of $\beta$-catenin thus preventing its nuclear translocation and transcriptional activation of lymphoid enhancer factor/T cell factor transcription factors (LEF/TCF) complex. A tightly regulated level of $\beta$-catenin signaling must be guaranteed for a healthy articular cartilage [22].

Previous studies have demonstrated that human osteoarthritis (OA) tissues over-express smad ubiquitin regulatory factor2 (Smurf2), whose conditional overexpression in mice is followed by inhibition and proteasomal degradation of GSK3 $\beta$, upregulation of $\beta$-catenin, and articular cartilage degeneration $[23,24]$. Metabolic Syndrome (MetS) is a global epidemic, affecting $23 \%$ of the general population with more than 2.5 fold prevalence in OA patients and indeed greatly worsen the risk of occurrence and progression of knee OA $[25,26]$. A study for the extent of GSK3 $\beta$ inactivation in OA knee cartilage explants found occurrence of articular 
Table 4: Association of haplotypes of SFRP4 and GSK3 $\beta$ genes with the hip lesions of ONFH

\begin{tabular}{|c|c|c|c|c|c|c|}
\hline SNPs & $\begin{array}{l}\text { Haplo- } \\
\text { type }\end{array}$ & $\begin{array}{c}\text { Bilateral } \\
n(\%)\end{array}$ & $\begin{array}{c}\text { Unilateral } \\
n(\%)\end{array}$ & $\chi^{2}$ & $P$ & OR $(95 \% C I)$ \\
\hline \multirow{4}{*}{$\begin{array}{l}\text { SFRP4 } \\
\text { rs1802073(A/C)- } \\
\text { rs1052981(C/T) }\end{array}$} & A-C & $23.64(13.0)$ & $10.68(8.5)$ & 1.53 & 0.22 & $1.612(0.753 \sim 3.453)$ \\
\hline & A - $\mathrm{T}$ & $69.36(36.7)$ & $45.32(36.0)$ & 0.146 & 0.70 & $1.096(0.684 \sim 1.755)$ \\
\hline & $\mathrm{C}-\mathrm{C}$ & $18.36(10.1)$ & $16.32(13.0)$ & 0.613 & 0.43 & $0.754(0.371 \sim 1.532)$ \\
\hline & $\mathrm{C}-\mathrm{T}$ & $70.64(38.8)$ & $53.68(42.6)$ & 0.444 & 0.51 & $0.855(0.538 \sim 1.357)$ \\
\hline \multirow{3}{*}{$\begin{array}{l}\text { GSK3 } \beta \\
\text { rs3732361(G/A)- } \\
\text { rs3755557(T/A) }\end{array}$} & A-A & $24.00(13.2)$ & $21.00(17.5)$ & 1.061 & 0.30 & $0.716(0.379 \sim 1.354)$ \\
\hline & A-T & $69.00(37.9)$ & $50.00(41.7)$ & 0.427 & 0.51 & $0.855(0.534 \sim 1.368)$ \\
\hline & G-T & $89.00(48.9)$ & $49.00(40.8)$ & 1.897 & 0.17 & $1.387(0.870 \sim 2.209)$ \\
\hline
\end{tabular}

chondrocytes with inactive GSK3 $\beta$ in obese patients thus hinting at GSK3 $\beta$ as one potential mechanism whereby metabolic factors impact on OA [27]. A Greek study was the first to show that GSK3ßrs334558 was related to PD, homozygous CC served a protective effect in PD [28], and a result from Australian population revealed that homozygous TT frequency of this SNP in PD patients was significantly increased compared to control subjects [29] while a result from Chinese population did not find any significant difference in allele-wise and genotype-wise analysis for GSK3ßrs334558 between PD patients and controls.

To our knowledge, there were no report of an association of SFRP4 and GSK3ßpolymorphisms with the development of ONFH. We speculated that SFRP4 and GSK $3 \beta$,as crucial proteins of Wnt signaling, might exert an important effect on the development of ONFH, and their polymorphisms might involved in ONFH risk. Therefore, we selected SFRP4 and GSK3ßgenes as potential candidate genes for susceptibility to ONFH. Our results demonstrated that the genotypes, allele, haplotype frequencies of 4 variants detected in the GSK3ßand SFRP4 genes and their association with the risk and clinical phenotypes of ONFH did not show statistical significance between $200 \mathrm{ONFH}$ patients and 177 controls. Nevertheless, the association of the variants in the SFRP4 and GSK3ßgenes with the risk and development of ONFH need to be further investigated with larger cohort studies.

The genes and their variants selection are a crucial element for exploring the effects of gene variants on a complex disease. The most important consideration is that new genes and their variants need to be identified to maximise the potential for associations [30]. Our major concern was the variants in promoter, 3-UTR, and coding region with the consideration of potential effects of them on the gene expression and gene function. Generally, variants in promoter and 3-UTR regions potentially contribute to differential gene expression, presumably affecting the binding of transcription factors to DNA. Therefore, we selected the 1 variant in promoter and 3-UTR region of GSK3 $\beta$ gene, the 1 variant in 3-UTR region of SFRP4 gene, respectively as target variants. Moreover, in view of the possible effects of variants in exons on protein expression, function or activity, we also selected the 1variant in coding region of SFRP4 gene, as target variant. In spite of the 4 variants detected in this study failing to show statistical association with ONFH risk, the optimal selection strategy will further improve the association investigation of the other variants in the SFRP4 and GSK3 3 genes as well as the other genes of Wnt signaling pathway with the risk and development of ONFH.

Our study has some limitations. First, the 377 cohort study attributes to smaller samples system, which may limit our statistical power to detect small differences between ONFH and control groups, especially for the subgroups analysis between the genotypes and clinical phenotypes. Second, we failed to detect the gene expression duo to the samples limitation. In future study, it is very significant to analyse the effects of the variants on the gene expression in larger sample system to identify their roles in the development of ONFH.

In conclusion, our results were not found the evidence supporting the 4 variants of SFRP 4 and GSK3 $\beta$ genes associated with the risk and development of ONFH in Chinese population, which suggest that the variants analyzed in this study are unlikely to be associated with susceptibility to ONFH.

\section{MATERIALS AND METHODS}

\section{Individuals}

Unrelated ONFH patients (132 men, 68 women; age: $52.8 \pm 9.7 \mathrm{yr})$ and 177 control individuals (112 men, 65 women; age: $50.73 \pm 11.02 \mathrm{yr}$ ) who visited The Department of Orthopedics from March, 2014 to June, 2015 and the Health Examination Centre of Second Clinical College of Jilin University, (Changchun, China) from October 2014 to December 2014 in the study, respectively. The ONFH patients concurrent with direct trauma, severe chronic diseases, such as cardiovascular diseases, congenital diseases, human immunodeficiency virus (HIV) infection, diabetes mellitus, renal dysfunction, and cancer were excluded. ONFH were diagnosed by evidence of osteonecrosis using plain radiographs in 
Table 5: Basic information of SNPS in GSK3 $\beta$ and SFRP4 genes

\begin{tabular}{lccccc}
\hline Gene & Chromosome & SNP ID & Allele & Minor Allele & Function \\
\hline GSK3及 & $3 \mathrm{q} 13.33$ & $\mathrm{rs} 3732361$ & $\mathrm{~A} / \mathrm{G}$ & $\mathrm{G}$ & $3^{\prime} \mathrm{UTR}$ \\
& & $\mathrm{rs} 3755557$ & $\mathrm{~T} / \mathrm{A}$ & $\mathrm{A}$ & Promoter \\
SFRP4 & \multirow{2}{*}{$7 \mathrm{p} 14.1$} & $\mathrm{rs} 1052981$ & $\mathrm{~T} / \mathrm{C}$ & $\mathrm{C}$ & $3^{\prime} \mathrm{UTR}$ \\
& & $\mathrm{rs} 1802073$ & $\mathrm{~A} / \mathrm{C}$ & $\mathrm{C}$ & Missense \\
\hline
\end{tabular}

UTR: untranslated regions

Table 6: List of PCR and sequencing primers of 4 variants in the SFRP4 and GSK3 $\beta$ genes

\begin{tabular}{|c|c|c|c|c|c|}
\hline Gene & SNP ID & PCR Primer & $\begin{array}{c}\text { Product } \\
\text { length(bp) }\end{array}$ & $\begin{array}{l}\text { Sequencing } \\
\text { primer }\end{array}$ & $\begin{array}{c}\text { Molecular } \\
\text { weight }\end{array}$ \\
\hline \multirow[t]{4}{*}{ SFRP4 } & rs1802073 & 5' ACGTTGGATGTTCTTCTTGGGACTGGCTGG3' & 86 & GTTTGGGAGCAGGAG & 4713.1 \\
\hline & & 5' ACGTTGGATGTCGTAGTAATCCCCCCAAAC 3' & & & \\
\hline & rs1052981 & 5'ACGTTGGATGCAGAGCTGAAGTCATTGTAA 3' & 132 & AAGTCATTGTAAAAAAGACACATTATA & 8307.5 \\
\hline & & 5'ACGTTGGATGTGTTTATGGTCTGCAGAAGG 3' & & & \\
\hline \multirow[t]{4}{*}{ GSK3ß } & rs3732361 & 5' ACGTTGGATGCACTGACGTATCAAAACCTG3' & 97 & gGACGTATCAAAACCTGATACTATTA & 7962.2 \\
\hline & & 5' ACGTTGGATGCAAATGAGAGAGTGACAGAG3' & & & \\
\hline & rs3755557 & 5'ACGTTGGATGGCAAGAGCCAGGTAATCTGA 3' & 113 & ccccATCTGATCAAATATAGGTCCTTT & 8169.3 \\
\hline & & 5'ACGTTGGATGTCTACCTGCAGAGTCATCTC 3' & & & \\
\hline
\end{tabular}

Stages 2, 3, and 4 of the Ficat Classification system [31]. According to etiological factors, ONFH patients were subgrouped into alcohol-induced (71 cases (39.7\%), idiopathic (64 cases $(34.0 \%)$, and steroid-induced osteonecrosis (47 cases $(26.3 \%)$, respectively. Steroidinduced osteonecrosis was defined by a history of taking prednisolone cumulative $2000 \mathrm{mg}$ or an equivalent over 21 days. Alcohol-induced osteonecrosis was defined by the consumption of more than $900 \mathrm{ml}$ of pure ethanol per week. The course of ONFH ranged from 0.5 months to 360 months, with an average of 71.75 months, and the clinical stages of ONFH consisted of 10 cases of stage II $(5.6 \%), 54$ cases of stage III $(30.2 \%)$ and 115 cases $(64.2 \%)$ of stage IV.

The unilateral and bilateral hips lesions were 76 cases $(42.5 \%)$ and 103 cases $(57.5 \%)$, respectively. There were 21 cases of ONFH patients who failed to undergo the clinical stages or aetiological classification duo to the defect of plain radiographs or unclear aetiological factors. Health control subjects were defined in the same way as reference [32]. All of the 377 participants were Han Chinese from northeast China. The study was approved by the ethics committee of the Second Clinical College of Jilin University, Changchun, China, and conformed to the current ethical principles of the Declaration of Helsinki. All participants provided informed consent for their taking part in the study.

\section{Genomic DNA extraction and variants selection}

Genomic DNA was extracted from whole blood samples using the genomic DNA extraction kit (DP318, TianGen, BeiJing, China) according to the manufacturer's protocols. The HapMap database and related literature
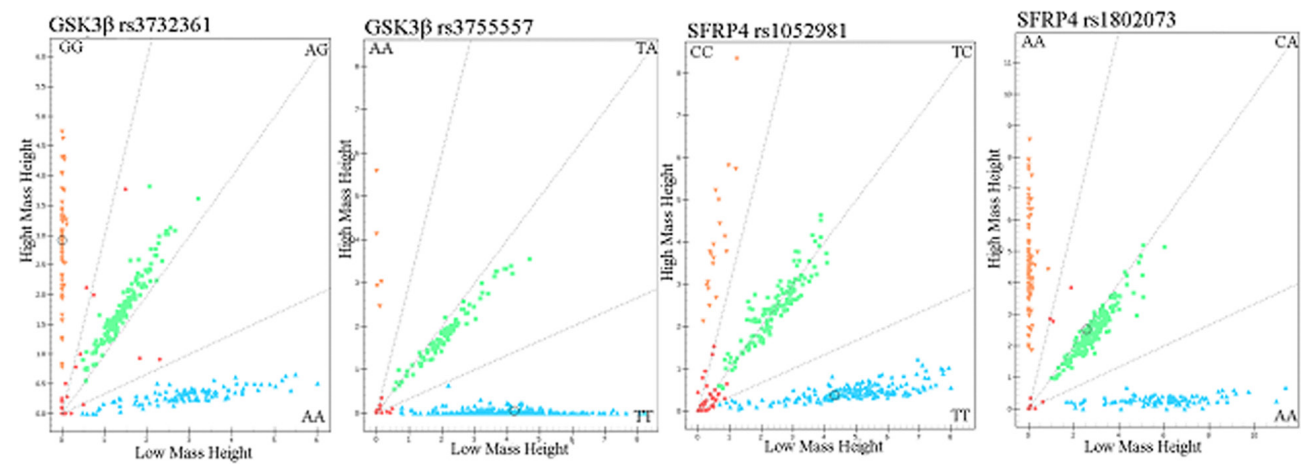

Figure 2: Call cluster plot of 4 variants genotyping in the GSK3ß and SFRP4 genes by MALDI-ToF-MS. The green plots represent heterozygous genotypes, yellow and blue plots represent major homozygous or minor homozygous genotypes in the call cluster plot of each variant, respectively. MALDI-ToF-MS: matrix-assisted laser desorption/ionization time-of-flight mass spectrometry. 
were used to select variants of the genes by analysing their population distribution in different countries, nationalities and regions, particularly in data from an Asian population. The database: http://gvs.gs. washington. edu /GVS138/ was used to select variants. The search scope of the genes was from the upstream 2000bp to downstream 1000bp of GSK3 $\beta$ and SFRP4 genes, respectively. The selection criteria of variants included in $\mathrm{r}^{2}>0.8$ or $\mathrm{D}^{\prime}=1$; Minority allele A frequencies $>0.05$. Rs1802073 (T/G) in coding region and $\mathrm{rs} 1052981(\mathrm{G} / \mathrm{A})$ in 3-UTR region of SFRP4 gene, rs3732361 (G/A) in 3-UTR region and rs3755557 $(\mathrm{A} / \mathrm{T})$ in promoter region of GSK $3 \beta$ gene were selected, shown in Table 5.

\section{Genotyping}

Primers for polymerase chain reaction and sequencing were designed by Sequenom Assay Design 3.1 software (Sequenom, San Diego, CA, USA) following the manufacturer's instructions, shown in Table 6.The quality inspection of the sequencing primer was completed by matrix assisted laser desorption ionization time-offlight mass spectrometry (MALDI-TOF). Mass ARRAY ${ }^{\circledR}$ platform (Sequenom Analyzer 4, Inc., San Diego, CA, USA) was used to analyse the 4 variants polymorphisms in the SFRP4 and GSK3 $\beta$ genes. The genotyping success rates for the 4SNPs were $>95 \%$, respectively. The linkage disequilibrium analysis and Call Cluster Plot of the 4SNPs are presented in Figure 1 and Figure 2, respectively.

\section{Statistical analysis}

Statistical analysis was followed a prior study of our group [32]. Briefly, Shesis software platform (http:// analysis.bio-X.cn/SHEsisMain.html) was used to analyse the Hardy-Weinberg equilibrium and haplotypes between the ONFH and control groups and their associations with the clinical phenotypes of ONFH. In addition, logistical regression analyses were performed to calculate the odds ratios (OR), 95\% confidence intervals (CI), and corresponding $p$-values of each variants controlling for age and sex as covariates. The genetic models of dominant, recessive, and codominant were considered. SPSS10.0 software $\left(\mathrm{X}^{2}\right.$ test) was used to analyse the association of the genes polymorphisms with clinical phenotypes of ONFH. A $p$-value of $<0.05$ was considered statistically significant.

\section{Author contributions}

Yang Song and Guizhen Zhang conceived the conception and designed the study; Zhenwu Du, Qiwei Yang, Ming Ren, and Qingyu Wang performed the acquisition, analysis, and interpretation of data; Yang Song, Gaoyang Chen, Haiyue Zhao, and Zhaoyan Li finished the experiment; Yang Song drafted the article;
Guizhen Zhang revised the article critically for important intellectual content and approved the final version to be submitted. All authors read and approved the final manuscript.

\section{ACKNOWLEDGMENTS}

This work was supported by the Project of Health Management Department of Jilin Province, China (Grant No. 20132003), the Project of Bethune Youth Foundation of Jilin University, China (Grant No. 2015409), the Department of Science and Technology of Jilin Province, China (Grant No.20140311006YY, 20150312022ZG), and the Development and Reform Commission of Jilin Province, China [Grant No. 2014G073, the project of application demonstration center of precision medicine for molecular diagnosis in Jilin Province (2016-2018)].

\section{CONFLICTS OF INTEREST}

The authors declare that they have no competing interests.

\section{REFERENCES}

1. Yavropoulou MP, Yovos JG. The role of the Wnt signaling pathway in osteoblast commitment and differentiation. Hormones. 2007; 6:279-294.

2. Kawai M, de Paula FJ, Rosen CJ. New insights into osteoporosis: the bone-fat connection. J Intern Med. 2012; 272:317-329.

3. Clevers H, Nusse R. Wnt/ $\beta$-catenin signaling and disease. Cell. 2012;149:1192-1205.

4. Macsai CE, Foster BK, Xian CJ. Role of Wnt signaling in bone growth, remodeling skeletal disorders and fracture repair. J Cell Physiol. 2008; 215:578-587.

5. Christodoulides C, Lagathu C, Sethi JK, Vidal-Plug A. Adipogenesis and Wnt signaling. Trends Endocrinol Metab. 2009; 220:16-24.

6. Mont MA, Cherian JJ, Sierra RJ, Jones LC, Lieberman JR. Nontraumatic osteonecrosis of the femoral head: where do we stand today? a ten-year update. J Bone Joint Surg Am. 2015; 97:1604-1627.

7. Kubo T, Ueshima K, Saito M, Ishida M, Arai Y, Fujiwara H. Clinical and basic research on steroid-induced osteonecrosis of the femoral head in Japan. J Orthop Sci. 2016; 21:407-413.

8. Microsurgery Department of the Orthopedics Branch of the Chinese Medical Doctor Association, Group from the Osteonecrosis and Bone Defect Branch of the Chinese Association of Reparative and Reconstructive Surgery, Microsurgery and Reconstruct. Chinese Guideline for the Diagnosis and Treatment of Osteonecrosis of the Femoral Head in Adults. Orthop Surg. 2017; 9:3-12. 
9. James AW. Review of signaling pathways governing MSC osteogenic and adipogenic differentiation. Scientifica (Cairo). 2013; 684736. https://doi. org/10.1155/2013/684736.

10. Estrada K, Styrkarsdottir U, Evangelou E, Hsu YH, Duncan EL, Ntzani EE, Oei L, Albagha OM, Amin N, Kemp JP, Koller DL, Li G, Liu CT, et al. Genome-wide meta-analysis identifies 56 bone mineral density loci and reveals 14 loci associated with risk of fracture. Nat Genet. 2012; 44:491-501.

11. Medina-Gomez C, Kemp JP, Estrada K, Eriksson J, Liu J, Reppe S, Evans DM, Heppe DH, Vandenput L, Herrera L, Ring SM, Kruithof CJ, Timpson NJ, et al. Metaanalysis of genome-wide scans for total body BMD in children and adults reveals allelic heterogeneity and agespecific effects at the WNT16 locus. PLoS Genet. 2012; 8:e1002718. https://doi.org/10.1371/journal.pgen.

12. Goldring, SR, Goldring MB. Eating bone or adding it: the Wnt pathway decides. Nat Med. 2007; 13: 133-134.

13. Webster RA, Blaber SP, Herbert BR, Wilkins MR, Vesey $\mathrm{G}$. The role of mesenchymal stem cells in veterinary therapeutics - a review. N Z Vet J. 2012; 60: 265-272.

14. Hernigou P, Beaujean F. Abnormalities in the bone marrow of the iliac crest in patients who have osteonecrosis secondary to corticosteroid therapy or alcohol abuse. J Bone Joint Surg Am. 1997; 79:1047-1053.

15. Seamon J, Keller T, Saleh J, Cui Q. The pathogenesis of nontraumatic osteonecrosis. Arthritis (Egypt). 2012; 601763. https://doi.org/10.1155/2012/601763.

16. Sheng H, Sheng CJ, Cheng XY, Zhang G, Lee KM, Leung KS, Qu S, Qin L. Pathomorphological changes of bone marrow adipocytes in process of steroid-associated osteonecrosis. Int J Clin Exp Pathol. 2013; 6:1046-1050.

17. Mahdi T, Hänzelmann S, Salehi A, Muhammed SJ, Reinbothe TM, Tang Y, Axelsson AS, Zhou Y, Jing X, Almgren P, Krus U, Taneera J, Blom AM, et al. Secreted frizzled-related protein 4 reduces insulin secretion and is overexpressed in type 2 diabetes. Cell Metab. 2012; 16:625-633.

18. Ehrlund A, Mejhert N, Lorente-Cebrián S, Aström G, Dahlman I, Laurencikiene J, Rydén M. Characterization of the Wnt inhibitors secreted frizzled-related proteins (SFRPs) in human adipose tissue. J Clin Endocrinol Metab. 2013; 98: E503-508.

19. Simsek Kiper PO, Saito H, Gori F, Unger S, Hesse E, Yamana K, Kiviranta R, Solban N, Liu J, Brommage R, Boduroglu K, Bonafé L, Campos-Xavier B, et al. Corticalbone fragility - insights from SFRP4 deficiency in Pyle's disease. N Engl J Med. 2016; 374:2553-2562.

20. Shao J, Yu M, Jiang L, Wu F, Liu X. Sequencing and bioinformatics analysis of the differentiallyexpressed genes in herniated discswith or without calcification. Int J Mol Med. 2017; 39:81-90.

21. Cohen P, Frame S. The renaissance of GSK3. Nat Rev Mol Cell Biol. 2001; 2:769-776.
22. Lories RJ, Corr M, Lane NE. To Wnt or not to Wnt: the bone and joint health dilemma. Nat Rev Rheumatol. 2013; 9:328-339.

23. Wu Q, Kim KO, Sampson ER, Chen D, Awad H, O'Brien T, Puzas JE, Drissi H, Schwarz EM, O'Keefe RJ, Zuscik MJ, Rosier RN. Induction of an osteoarthritis-like phenotype and degradation of phosphorylated Smad3 by Smurf2 in transgenic mice. Arthritis Rheum. 2008; 58:3132-3144.

24. Wu Q, Huang JH, Sampson ER, Kim KO, Zuscik MJ, O'Keefe RJ, Chen D, Rosier RN. Smurf2 induces degradation of GSK-3beta and upregulates beta-catenin in chondrocytes: a potential mechanism for Smurf2-induced degeneration of articular cartilage. Exp Cell Res. 2009; 315:2386-2398.

25. Zhuo Q, Yang W, Chen J, Wang Y. Metabolic syndrome meets osteoarthritis. Nat Rev Rheumatol. 2012; 8:729-737.

26. Yoshimura N, Muraki S, Oka H, Tanaka S, Kawaguchi H, Nakamura K, Akune T. Accumulation of metabolic risk factors such as overweight, hypertension, dyslipidaemia, and impaired glucose tolerance raises the risk of occurrence and progression of knee osteoarthritis: a 3-year follow-up of the ROAD study. Osteoarthritis Cartilage. 2012; 20:1217-1226.

27. Guidotti S, Minguzzi M, Platano D, Cattini L, Trisolino G, Mariani E, Borzì RM. Lithium chloride dependent glycogen synthase kinase 3 inactivation links oxidative DNA damage, hypertrophy and senescence in human articular chondrocytes and reproduces chondrocyte phenotype of obese osteoarthritis patients. PLoS One. 2015; 10:e0143865. https://doi.org/10.1371/journal.pone.

28. Landrigan PJ, Sonawane B, Butler RN, Trasande L, Callan R, Droller D. Early environmental origins of neurodegenerative disease in later life. Environ Health Perspect. 2005;113:1230-1233.

29. Kwok JB, Hallupp M, Loy CT, Chan DK, Woo J, Mellick GD, Buchanan DD, Silburn PA, Halliday GM, Schofield PR. GSK3B polymorphisms alter transcription and splicing in Parkinson's disease. Ann Neurol. 2005; 58:829 - 839.

30. Johns N, Tan BH, MacMillan M, Solheim TS, Ross JA, Baracos VE, Damaraju S, Fearon KC. Genetic basis of interindividual susceptibility to cancer cachexia: selection of potential candidate gene polymorphisms for association studies. J Genet. 2014; 93:893-916.

31. Ficat RP. Idiopathic bone necrosis of the femoral head. Early diagnosis and treatment. J Bone Joint Surg Br. 1985; 67:3-9.

32. Song Y, Du Z, Ren M, Yang Q, Wang Q, Chen G, Zhao H, Li Z, Wang J, Zhang G. Association of gene variants of transcription factors PPAR $\gamma$, RUNX2, Osterix genes and COL2A1, IGFBP3 genes with the development of osteonecrosis of the femoral head in Chinese population. Bone. 2017; 101:104-112. 